\title{
Coronavirus Infections of Animals: Future Risks to Humans
}

\author{
I. M. Donnik ${ }^{a}$, Ig. V. Popov ${ }^{b, c}$, S. V. Sereda ${ }^{b}$, Il. V. Popov ${ }^{c}$, M. L. Chikindas ${ }^{b, d}$, and A. M. Ermakov ${ }^{b, *}$ \\ ${ }^{a}$ Russian Academy of Sciences, Moscow, 119991 Russia \\ ${ }^{b}$ Don State Technical University, Rostov-on-Don, 344000 Russia \\ ${ }^{c}$ Rostov State Medical University, Rostov-on-Don, 344022 Russia \\ ${ }^{d}$ Health Promoting Naturals Laboratory, School of Environmental and Biological Sciences, Rutgers, \\ The State University of New Jersey, New Brunswick, NJ 08901 USA \\ *e-mail: amermakov@yandex.ru \\ Received May 4, 2020; revised June 27, 2020; accepted July 17, 2020
}

\begin{abstract}
Coronaviruses have tremendous evolutionary potential, and three major outbreaks of new human coronavirus infections have occurred in the recent history of humankind. In this paper, the patterns of occurrence of new zoonotic coronavirus infections and the role of bioveterinary control in preventing their potential outbreaks in the future are determined. The possibility of SARS-CoV-2 infection in companion animals is considered. Diverse human activities may trigger various interactions between animal species and their viruses, sometimes causing the emergence of new viral pathogens. In addition, the possibility of using probiotics for the control of viral infections in animals is discussed.
\end{abstract}

DOI: $10.1134 / \mathrm{S} 1062359021010052$

\section{INTRODUCTION}

Coronaviruses (Coronaviridae, $\mathrm{CoV}$ ) are a family of pathogenic viruses that attack humans and animals and cause diseases of the respiratory, gastrointestinal, and nervous systems with varying degrees of severity. The CoV family includes two subfamilies: Coronavirinae subdividing into four genera (Alphacoronavirus, Betacoronavirus, Gammacoronavirus, and Deltacoronavirus) and Torovirinae consisting of two genera (Torovirus and Bafinivirus). The genus Betacoronavirus subdivides into several subgenera designated, before the revision of taxonomy in 2019, by the first four letters of the Latin alphabet. Now it is commonly considered that this genus consists of the following subgenera: Embecovirus (the former subgenus A), Sarbecovirus (the former subgenus B), Merbecovirus (the former subgenus C), Nobecovirus (the former subgenus D), and the subgenus Hibecovirus distinguished for the first time (Li et al., 2019). The unique mechanism of $\mathrm{CoV}$ replication provides high-frequency genetic recombinations in their RNAs and subsequent mutations, altogether allowing the rapid adaptation of $\mathrm{CoV}$ to new hosts and ecological niches (Ji et al., 2020; Lu et al., 2020).

The mutation activity favors changes in $\mathrm{CoV}$ virulence; however, the role of animal carriers is not the least important here, because they are involved in the global ecosystem, particularly as the core components of zoonotic viral infections: the primary and secondary reservoirs (Omrani et al., 2015; Mohd et al., 2016; Shi et al., 2017). At the moment, based on retrospec- tive epidemiological data, it may be asserted confidently that beta-coronaviruses such as SARS-CoV, MERS-CoV, and SARS-CoV-2 have the greatest emergent zoonotic potential. It should be noted that the emergence and distribution of these viruses occur with the involvement of both domestic and wild animals, in particular, bats (Sun et al., 2020). The peculiarities of antiviral immune responses of these animals have formed a good foundation for more intensive development of progenitors of the above three viruses (Li et al., 2019). At present, the scientific community faces the problem of creating a strategy to prevent a potential fourth outbreak of new coronaviral infection.

\section{MATERIALS AND METHODS}

The present systematic review is based on Scopus, The Cochrane Database, MEDLINE/PubMed Database, Embase-Elsevier, Web of Science Core Collection, and eLIBRARY (2003-2020) database searching by the following combinations of keywords and the SQL operator: "coronavirus" AND ("animal" OR "bat" OR "dromedary camel" OR "civet" OR "pangolin" OR "cat" OR "dog” OR "ferret" OR "animal model"). We used information from many (91) extensive reviews, as well as the results of systematic analyses and research works discussing the fundamental and clinical aspects of coronavirus infections in different animal species and their zoonotic potential. 


\section{RESULTS AND DISCUSSION}

It has been established that all of the known human coronavirus infections are zoonotic. The systematic review (Ye et al., 2020) presents seven examples of detected human $\mathrm{CoV}$ formed with the involvement of no fewer than five representatives of different orders of mammals.

Animals are considered the primary evolutionary hosts of human $\mathrm{CoV}$ in the event of detection of a precursor virus homologous to the human one at the nucleotide sequence level. This virus usually has no marked virulence against the host animal, and its carriage is asymptomatic. In most cases, CoV must overcome the interspecies barrier to infect humans, which occurs due to the diversity of genetic and phenotypic features of the virus resulting from replication mistakes, e.g., inactivation of the exoribonuclease (Ogando et al., 2019). The precursor virus often exhibits pathogenicity when it infects an intermediate host, which plays the role of a reservoir for intensive propagation. In the case of repeated contacts with an infected animal, the precursor virus has a great chance to be transmitted to a human being and, if $\mathrm{CoV}$ are capable of human-to-human transmission, they do not lose the ability to develop and can adapt to a new host organism, losing their virulent properties. For example, MERS-CoV has the highest lethality among the seven detected CoV. At the same time, MERS$\mathrm{CoV}$ has the lowest contagiousness among people compared to other representatives of this group of viruses (Omrani et al., 2015; Chu et al., 2020). At the same time, HCoV-229E, HCoV-OC43, HCoV-NL63, and $\mathrm{HCoV}-\mathrm{HKU} 1$ do not cause any serious or systemic inflammatory diseases in people, indicating the adaptation of these viruses to new hosts (Corman et al., 2015; Milewska et al., 2018; Cui et al., 2019). There is an interesting situation with SARS-CoV-2: in the course of evolution, the contagious and virulent properties of this virus formed most favorably for its pandemic spread. However, this virus demonstrates the logic of adaptive prevalence of contagiousness over virulence. Tang et al. discovered two types of SARSCoV-2 (the more virulent L-type and the less virulent S-type) and ascertained that transmission of the S-type causing relatively less severe inflammatory diseases began to prevail over the L-type due to the sanitary and epidemiological control measures taken with the spread of this virus in China (Tang et al., 2020).

Thus, for detecting potential emergent zoonotic coronavirus infections, it is necessary to consider the variants of their asymptomatic carriage in animals, especially if the infectious agent is a member of the genus Betacoronavirus.

The members of the order Chiroptera are involved in numerous epidemiological outbreaks of zoonotic infections, in particular, those common for other animals and for people. The human viruses with precursors found in these animals include Filoviridae (Ebola and Marburg) (Goldstein et al., 2018; Forbes et al., 2019), Paramyxoviridae (Nipah, Hendra) (Drexler et al., 2012), and certainly CoV (Ye et al., 2020). In addition, it should be noted that now there are no fewer than 30 established CoV species that use Chiroptera as a natural reservoir (Wong et al., 2019). One of the favorable factors for the existence of such a great number of zoonotic viruses is the species diversity of the order Chiroptera (>1300 species) and, consequently, the great number of different cells and receptors that infectious agents can interact with. The fact that wing-handed animals are the only mammals that can fly over long distances, thereby increasing the number of contacts with other animals, also plays an important role in extensive interspecies transmission of zoonotic viruses (Hawkins et al., 2019).

However, the major cause why these animals are considered to be the ideal "incubators" of new pathogenic viruses, including $\mathrm{CoV}$, is asymptomatic virus carriage determined by the limited immunoinflammatory responses. Viruses, upon entering into most mammalian organisms, activate proinflammatory cytokins, thereby leading to inflammatory diseases and lethal outcomes (Tseng et al., 2012; Collins et al., 2014). A recent study (Brook et al., 2020) has demonstrated that the interaction between the cells of the Old World fruit bats (Pteropodidae) in vitro and different subtypes of Indiana vesiculoviruses results in a rather quick immune response, which however induces highfrequency replication of the virus in cell culture. In addition, it has also been shown that the antiviral interferon-mediated response of bats does not cause an inflammatory response sufficient for cell damage, which in turn prolongs the supposed persistence of viral infection. These results are confirmed by a number of previous studies. For example, is was shown for Chiroptera that their NF- $\kappa \mathrm{B}$ signaling pathways are degenerated (Zhang et al., 2013) and the activity of NLRP3-inflamasomes is suppressed as compared to those in other animals (Ahn et al., 2019). This is a basis for the limited inflammatory response and asymptomatic course of viral infections. It has also been shown that the enhanced NKG2/CD94-mediated regulation of NK-cells and the low expression of the major molecules of class I histocompatibility in fruit bats can prevent the function of NK-cells (Pavlovich et al., 2018).

All these peculiar features of immunity make Chiroptera organisms an ideal environment for the development and replication of a great number of viruses, in particular, CoV. Some data also show that reactive oxygen species formed as a result of active metabolism in these mammals can have an additional mutagenic effect on CoV by affecting the RNA-dependent RNA polymerase (Zhang et al., 2013).

Thus, wing-handed animals are dangerous as the first link in the chain of emergent coronavirus infections. The $\mathrm{CoV}$ that have acquired higher replication 
activity due to long-term persistence in Chiroptera organisms have a good chance of acquiring virulent properties against new hosts during interspecies transmission, as probably occurred during the evolutionary development of SARS-CoV, MERS-CoV, and SARSCoV-2.

The direct transmission of $\mathrm{CoV}$ from Chiroptera to humans is unlikely because of the low frequency of contacts with these animals. Therefore, in most cases human $\mathrm{CoV}$ have passed through the stage of another animal carrier as an intermediate host during interspecies transmission.

The first outbreak of human coronavirus infection was caused by SARS-CoV in November 2002, in Guangdong province of China (Perlman et al., 2009). The outbreak initiated extensive research with the purpose to find out the source of infection. In 2003, a SARS-like CoV with $99.8 \%$ homology to SARS-CoV was found in workers of the animal market in Shenzhen and in animals, in particular, Himalayan palm civets Paguma larvata and raccoon dogs Nyctereutes procyonoides (Guan et al., 2003). The experimental modeling of coronavirus infection showed that civets were susceptible to SARS-CoV and to SARS-like $\mathrm{CoV}$ and thus considered to be an animal reservoir (Wu et al., 2005); a little later, the supposed CoV-precursor with $95 \%$ nucleotide sequence identity to SARS-CoV was found in the Chinese rufous horseshoe bat Rhinolophus sinicus (Lau et al., 2005; Li et al., 2005), so that the chain of viral transmission and evolution was finally established.

We believe it necessary to mention several important facts by the example of this outbreak. Firstly, it is known that Chiroptera had never been considered as a reservoir of zoonotic viral infections before the detection of the probable precursor of SARS-CoV (Wong et al., 2019). Hence, humans may find other members of the Animal Kingdom with their organisms being an ideal environment for the "incubation" of new emergent viral infections. Secondly, antibodies against SARS-like CoV have been identified only in the Himalayan palm civets found in the market of wild animals; no antibodies were detected in domestic or wild representatives of this species (Tu et al., 2004). This circumstance may indicate that there is no need for a large number of individuals to be involved in the interspecies transmission of $\mathrm{CoV}$ as the intermediate link. Thirdly, ten viral infections were reliably detected in the entire family of Viverridae, including civets, according to a recent systematic review (Wicker et al., 2017), and only one of them was of coronaviral origin. Consequently, the intermediate link of new emergent viral infections with an epidemic potential can be any animal that is in repeated close contact with a human being. The presence of coronavirus infection in the anamnesis of the species is not necessary.

The second episode of unknown coronavirus infection caused by MERS-CoV has some differences from the scenario of SARS-CoV transmission and the development described above. The virus was identified for the first time in 2012 in Saudi Arabia (MilnePrice et al., 2014); the genetically similar CoV of Chiroptera (CoV-HKU4, CoV-HKU5 and CoV-HKU25) established later were homologous by $75-87 \%$ to MERS-CoV. All these viruses use dipeptidyl peptidase-4 (DPP4) as a receptor for cell invasion (van Boheemen et al., 2012; Lau et al., 2018; Luo et al., 2018). However, in contrast to SARS-CoV, MERS$\mathrm{CoV}$ homologous by $100 \%$ to the virus isolated from humans was identified in an animal (supposedly the natural reservoir), namely, the Arabian camel Camelus dromedarius (Raj et al., 2014a). This fact indicates that MERS-CoV is evolutionarily more distant from the $\mathrm{CoV}$ of Chiroptera and the period from transmission of the potential $\mathrm{CoV}$-precursor from Chiroptera to camels till formation of MERS-CoV is longer. In addition, the fact that MERS-CoV potentially originated from the $\mathrm{CoV}$ of Chiroptera is indicated by the fecaloral route of transmission, which is more typical of the latter (Samara and Abdoun, 2014).

In contrast to the coronavirus infections of civets, those of Camelidae are quite frequent, and some of them can even overcome the interspecies barrier and be transmitted to humans, thereby becoming zoonotic. For example, Corman et al. in 2018 published the data that $\mathrm{HCoV}-229 \mathrm{E}$ causing nonlethal infections of respiratory tracts can be transmitted from camels to humans by a route analogous to the transmission routes of MERS-CoV, demonstrating the important role of camels as a reservoir of coronavirus infections (Corman et al., 2018). In 2014, Woo et al. reported on the identification of a new $\mathrm{CoV}$ from the genus Betacoronavirus, DcCoV UAE-HKU23, in dromedaries of Central Asia; in 2016, antibodies against this $\mathrm{CoV}$ were found in $98.3-100 \%$ of dromedaries in this region (Woo et al., 2014, 2016). An article published in 2019 was devoted to the genetic diversity of various UAE-HKU23 strains, and its authors supposed that the evolutionary development of this $\mathrm{CoV}$, which is based on acquisition of new genetic properties during replication, proceeds by the pathway of MERS-CoV, being evidence of its increasing emergence potential (So et al., 2019).

Camelidae are an ideal intermediate host for zoonotic infections, because in some regions they have close and repeated contacts with people and are used for milk and meat production and as draft animals (Widagdo et al., 2019). In addition, dromedaries are a reservoir of 37 zoonotic infections, with 13 of them being viral (Zhu et al., 2019).

Dromedaries can be carriers of coronavirus infection occurring in other members of the family Camelidae. 1309 samples of rectal and nasal smears taken from camels in Saudi Arabia in the period from May 2014 to April 2015 were shown to contain two members of the genus Betacoronavirus (MERS-CoV and 
HKU23-CoV) and one member of the genus Alphacoronavirus, which proved to be genetically homologous to the $\mathrm{CoV}$ detected in the alpacas Vicugna pacos in the United States in 2007 and the human HCoV-229E (Sabir et al., 2016). Later, the whole genome sequencing of the detected alpha- $\mathrm{CoV}$ showed that this virus was homologous by $92.2 \%$ to $\mathrm{HCoV}-229$, and a common ancestor of these two viruses could have been transmitted from alpacas to humans in the 1960s. This fact was established by comparing different alpha-CoV strains identified within the period from 1962 to 2003 (Crossley et al., 2010, 2012).

Camelidae are not the only agricultural animals involved in the transmission chains of $\mathrm{CoV}$, because all agricultural ruminant animals can be infected with $\mathrm{CoV}$, which causes economic damage to global livestock farming, and some $\mathrm{CoV}$ of these animals are considered precursors of human viruses. The spread of $\mathrm{CoV}$ in cattle is favored by factors such as high livestock population density in a limited territory, which is a favorable condition for rapid transmission of viruses by means of the fecal-oral and airborne routes (Heckert et al., 1990; Decaro et al., 2008). It is reliably known that the immune resistance of animals decreases in winter, leading to the enhanced frequency of occurrence of diseases caused by coronavirus infections (Carman et al., 1992). It is altogether a suitable environment for the formation of potential zoonotic CoVs. Vijgen et al. supposed that $\mathrm{HCoV}-\mathrm{OC} 43$ developed from a common ancestor with the cattle $\mathrm{CoV}$ when overcoming the interspecies barrier in the $1890 \mathrm{~s}$ (Vijgen et al., 2005, 2006).

To date, one of the most frequently discussed subjects is the possible involvement of companion animals in the chain of transmission of emergent coronavirus infections, because these animals are in the closest contact with people. So far, there is insufficient evidence for stating that small domestic animals are involved in the genesis and spread of emergent $\mathrm{CoV}$.

The only definitely known CoV causing an infectious inflammatory disease in cats Felis silvestris catus is feline $\mathrm{CoV}$, which belongs to the genus Alphacoronavirus and subdivides into two types based on the genetic and antigenic difference in the spike protein (Jaimes et al., 2018; Felten and Hartmann, 2019). In real life, most coronaviral feline peritonites are caused by type I feline $\mathrm{CoV}$; type II is relatively less widespread, as this $\mathrm{CoV}$ was a result of genetic recombination with canine $\mathrm{CoV}$, which makes it less contagious for cats (Le Poder, 2011). This fact is confirmed by the recent study by Zhao et al., where serological screening showed that $75(54.7 \%)$ and $26(19.9 \%)$ out of 137 plasma samples were seropositive towards type I and II feline $\mathrm{CoV}$, respectively. At the same time, all feline plasma samples seropositive towards type II were also positive towards type I, which is indicative of the phenomenon of cross-reactivity, because not all animals of this group were infected with type I feline $\mathrm{CoV}$ (Zhao et al., 2019).

Cats are sometimes used as model experimental animals for reproducing different viral infections in order to investigate their pathological aspects, the possibility of transmission between individuals, and the approbation of treatment approaches. For example, successful techniques of experimental reproduction of feline coronavirus infection using the canine $\mathrm{CoV}$ and the human HCoV-229E were described in 1984-1985 (Barlough et al., 1984, 1985). The experimental data published in 2003 showed that this virus was detected in samples of nasal smears from cats four and six days after intra-tracheal inoculation of $10^{6} \mathrm{U}$ of a $50 \%$ infective dose of SARS-CoV in the absence of typical symptoms. It is evidence that the organisms of these animals are susceptible to infection by one more human CoV. In addition, cases of SARS-CoV transmission to other laboratory cats placed into a closed cage with an infected individual have been described (Martina et al., 2003). An analogous experimental study confirmed these data and additionally described the changes in the respiratory tracts during the reproduction of SARS-CoV infection typical of tracheobronchoadenitis (van den Brand et al., 2008).

Let us note that all model works on the reproduction of coronavirus infections in cats are accompanied by comparison with the control and experimental groups of polecats Mustela putorius, which are also quite popular companion animals. All works describe more marked inflammatory and immune responses in these animals, which are more like those in humans by nature, making polecats a more convenient model for studying human pathologies (Martina et al., 2003; van den Brand et al., 2008; Gong et al., 2018). However, attempts to reproduce coronavirus infection with MERS-CoV failed as polecats proved to be immune to this viral agent (Raj et al., 2014b). It has been shown that other laboratory animals, namely, the New Zealand white rabbit Oryctolagus cuniculus, can be appropriate for in vitro modeling of MERS-CoV respiratory infection (Haagmans et al., 2015), so that the necessity of using genetically modified mice Mus musculus for this purpose can be reduced (Agrawal et al., 2015).

Immediately after the outbreak of the novel coronavirus infection in December 2019 in the city of Wuhan of Hubei Province in China, studies were started to identify the viral agent, which was later designated as SARS-CoV-2 due to its genetic and phenotypic similarity to SARS-CoV, as well as due to the similar clinical courses of diseases caused by these viruses (Gorbalenya et al., 2020; Yang et al., 2020). After finding out that cell invasion by SARS-CoV-2 occurs via the interaction with the angiotensin-converting enzyme-2 (ACE2), scientists put forward the hypothesis that this virus could be studied in the same model animals that were used to simulate the infection caused by SARS-CoV. Shi et al. performed an exten- 
sive experimental study, which included numerous species of small domestic and agricultural animals exposed to intranasal inoculation with $10^{5}$ plaqueforming units of SARS-CoV-2. By analogy to SARS$\mathrm{CoV}$, only cats (to a lesser extent) and polecats (to a greater extent) responded to SARS-CoV-2 (Shi et al., 2020), which is undoubtedly associated with the similar structures of ACE2 in these animals and in humans (Guo et al., 2008). The results of studies by Shi et al. raised numerous questions concerning the potential involvement of small domestic animals, in particular cats, in the routes of SARS-CoV-2 transmission.

We believe it necessary to mention the unnatural process of infecting cats with SARS-CoV-2 in this experimental study because of the very low probability of real conditions for direct intranasal introduction of an extremely high dose of a viral pathogen. The study provided valuable data indicating that cats and polecats can be used as model animals, but no more than that. For comparison, we believe it necessary to refer to the previously mentioned work by Haagmans et al., who studied rabbits after intranasal and intratracheal administration of $1 \times 10^{6}$ and $4 \times 10^{6} \mathrm{U}$ of the $50 \%$ infective dose of MERS-CoV, respectively (Haagmans et al., 2015). The population of rabbits worldwide is indisputably greater that the population of dromedaries (Di Vincenti et al., 2016; Sazmand et al., 2019), and not a single case of MERS-CoV transmission between rabbits and humans has been documented over eight years since the moment of identification of this virus in the first patient. Therefore, it is not advisable to extrapolate the data obtained from laboratory experiments to reality. The response of any animal to a human viral pathogen, with the exception of involvement of this animal in the transmission chain, is only evidence of the similarity between molecular and biochemical processes in the two organisms. This fact also allows this animal to be used as a potential model object to study the ways of controlling human viral infection.

However, the situation with cats is far more complicated due to publications of the results of large-scale serological surveys, one of them performed in the city of Wuhan. It was shown that 15 out of 102 plasma samples from cats taken during the outbreak of COVID-19 were seropositive towards the receptor binding domain of SARS-CoV-2, which is indicative of their potential infection, while 39 samples taken from March to May 2019 were seronegative. It is important that the highest neutralization titer was observed in three cats, whose hosts had been infected with COVID-19 (Zhang et al., 2020). At the same time, it was reported that all nine cats included in the study did not showed any signs of SARS-CoV infection by the results of RT-PCR or antibodies against this virus in blood by the results of immunoprecipitation (Temmam et al., 2020). In addition, one should not disregard the cases of SARS$\mathrm{CoV}-2$ infection in different representatives of the family Felidae in zoos, which have been reported by mass media, though there was little information about the research methods used. When discussing the above-described studies, one should be guided by the principles of medicine and veterinary based on evidence and, therefore, not to make any final conclusions about the possibility of infection of cats with SARS-CoV-2 from humans under real conditions and, all the more so, reverse transmission.

Nevertheless, we assume the possibility of infection of representatives of the family Felidae with the new CoV due to the similarity of the molecular structure of the receptor target of this virus, but only under the conditions of very close and repeated contact with the infected human, when the total titer of the virus transmitted by the airborne route reaches the values close to those obtained by experimental modeling. However, under real conditions, such a concatenation of circumstances is extremely unlikely. In addition, one cannot forget the first outbreak of coronaviral infection caused by SARS-CoV, to which a cat also proved to be susceptible during experimental infection (Martina et al., 2003). Within 18 years, the scientific literature has not described a single confirmed case of SARS-CoV transmission by cats among regional populations or, moreover, cases of reverse transmission of this infection to humans.

We are sure that, if the SARS-CoV-2 infection of cats is confirmed, these animals will be a biological dead end for this virus. In addition, we believe that discussion of the fact of SARS-CoV-2 carriage and transmission by cats critically needs a large-scale cohort clinical trial, double-blind and randomized, which will exclude the effect of the human factor on the results, because their incorrect interpretation might lead to irreversible consequences. In addition, this study should be performed by the methods for detecting viral subgenomic RNA, which will most probably indicate the fact of SARS-CoV-2 replication in animal cells.

The situation with dogs (Canis lupus familiaris) is much more interesting. At present, two canine CoVs have been identified: one of them is a member of the genus Alphacoronavirus and causes inflammatory intestinal diseases (Decaro and Buonavoglia, 2008, 2011 ); the other is a member of the genus Betacoronavirus and affects the respiratory organs (Erles et al., 2007; Lu et al., 2017). It seems that both viruses demonstrate a high replication activity and appropriate rapid evolutionary development. The canine intestinal $\mathrm{CoV}$ was discovered in 1971 by Binn et al., who isolated it from working dogs with acute viral enteritis in Germany (Binn et al., 1974). Later it was divided into two types with respect to genotypic differences (Decaro et al., 2010a). It should be noted that the types of canine intestinal $\mathrm{CoV}$ are homologous to the analogous types of feline CoV (Decaro et al., 2010b), while type II in turn subdivides into two subtypes IIa 
and IIb on the basis of genetic differences that were a result of recombination with the virus of transmissible gastroenteritis of the pig Sus scrofa domesticus and acquisition of common characteristics (Decaro et al., 2009). The canine respiratory $\mathrm{CoV}$ was detected in 2003 in Great Britain. Determination of the evolutionary origin of this virus demonstrated a close relationship between the canine respiratory $\mathrm{CoV}$, the bovine $\mathrm{CoV}$, and $\mathrm{HCoV}-\mathrm{OC} 43$, being also indicative of a common precursor virus (Erles and Brownlie, 2008). It was possible to reproduce experimentally the infection in puppies using the bovine $\mathrm{CoV}$; hence, the researchers supposed that the precursor of the canine respiratory virus could have been transmitted to dogs from livestock (Kaneshima et al., 2007), which correlates with the assumption of the same origin of HCoV-OC43 (Vijgen et al., 2005, 2006).

Thus, the data on the homology between different $\mathrm{CoV}$ species suggest that dogs are involved in various routes of interspecies transmission of these viruses. Just like with cats, the scientific community has raised a query about the possibility of SARS-CoV-2 infection in dogs and their involvement in the transmission of infection. In our opinion, the most interesting publication is the work of Xia, who put forward the hypothesis that stray dogs of Hubei Province can be natural reservoirs of the SARS-CoV-2 precursor and that the high content of antiviral protein ZAP in the intestinal tissue of dogs could provoke the development of a potential precursor virus to acquire the ability to resist the ZAP-associated immune response by means of the adaptive reduction of $\mathrm{CpG}$-dinucleotides in the viral RNA (Xia, 2020).

The hypothesis is of particular interest, and we are sure that the principle of such interaction between ZAP proteins of the host and $\mathrm{CpG}$-dinucleotides of $\mathrm{CoV}$ can find its place in bioengineering. However, we are convinced that the probability of this hypothesis about the SARS-CoV-2 origin is unlikely the reasons stated below.

Firstly, in the discussion, the author does not take into account the study in which dogs proved to be unsusceptible to SARS-CoV-2 in case of an intranasal inoculation of an extremely high amount of plaqueforming units of the virus (Shi et al., 2020), while experimental modeling in the animals supposed to be $\mathrm{CoV}$ reservoirs showed the marked signs of infection: civets were susceptible to SARS-CoV (Xiao et al., 2008) and dromedaries were susceptible to MERSCoV (Adney et al., 2014).

Secondly, for the several months of the pandemic, SARS-like CoV were not identified and the antibodies to these viruses were not detected in dogs from Hubei Province. Due to the facts mentioned above, we are convinced that dogs are not involved in SARS-CoV-2 transmission and even the possibility of their carriage as a biological dead end is very unlikely.
It should be noted that five out of seven primary reservoirs of zoonotic $\mathrm{CoV}$, including the most dangerous SARS-CoV, MERS-CoV, and SARS-CoV-2, are different representatives of the order Chiroptera. However, it does not imply that only these animals are epidemiologically hazardous for humans: rodents (Rodentia), just like other orders of mammals, can also be a potential reservoir for a new outbreak of coronaviral infection.

When analyzing the evolutionary pathways of the human $\mathrm{CoV}$, we noted several regularities being a basis for proposing two scenarios for emergent $\mathrm{CoV}$ with different extents of human intervention in wildlife (Fig. 1). The first scenario does not imply any marked anthropogenic effects on the chain of $\mathrm{CoV}$ transmissions, namely, intentional invasion to the vital activity of wild animals leading to encounters between animal species, the areas of which do not overlap under natural conditions. For example, it is certain that MERS$\mathrm{CoV}$ has circulated in the population of dromedaries over many decades, as is confirmed by the lower genetic affinity with the potential precursors of $\mathrm{CoV}$ in bats (75-87\%) compared to SARS-CoV (95\%) (Mohd et al., 2016; Lau et al., 2018; Luo et al., 2018). The steady development of MERS-CoV in dromedaries is also indicated by the fact that viruses with $100 \%$ identity were detected in animals and in humans, as well as the necessity of contact between reservoir animals and humans for infection and the highest lethality rate for humans (34.4\%) (Petrosillo et al., 2020). All these facts are indicative of the consistent and steady evolution of MERS-CoV: the virus has entered human organisms only recently, which accounts for its low adaptation to the new host demonstrated by comparatively low human-to-human transmission (Petrosillo et al., 2020).

We suppose that SARS-CoV, compared to MERS$\mathrm{CoV}$, developed much more rapidly because of human invasion in wildlife. As is known, one of the most likely primary focuses of infection was the animal market of Shenzhen providing ideal conditions for mixing the microbiotas of different species. The cage management of a great number of animals taken from distant natural habitats within a limited area has an unfavorable effect on the resistance of their immune systems due to chronic stress which, together with noncompliance with sanitary rules, favors the interspecies transmission of viral microflora and enhanced replication activity of $\mathrm{CoV}$ during the adaptation to new hosts.

Such sublimation is a spatio-temporal shift due to the encounter of the viral microbiotas of animals that could never have had contact with each other without human intervention in the natural environment. Hence, it is impossible to predict the vector of genetic development of $\mathrm{CoV}$ under such conditions and there is a risk of emergence of $\mathrm{CoV}$ with unknown characteristics. In addition, as a result of such uncontrolled transmission, CoV has no time to adapt to a single ani- 


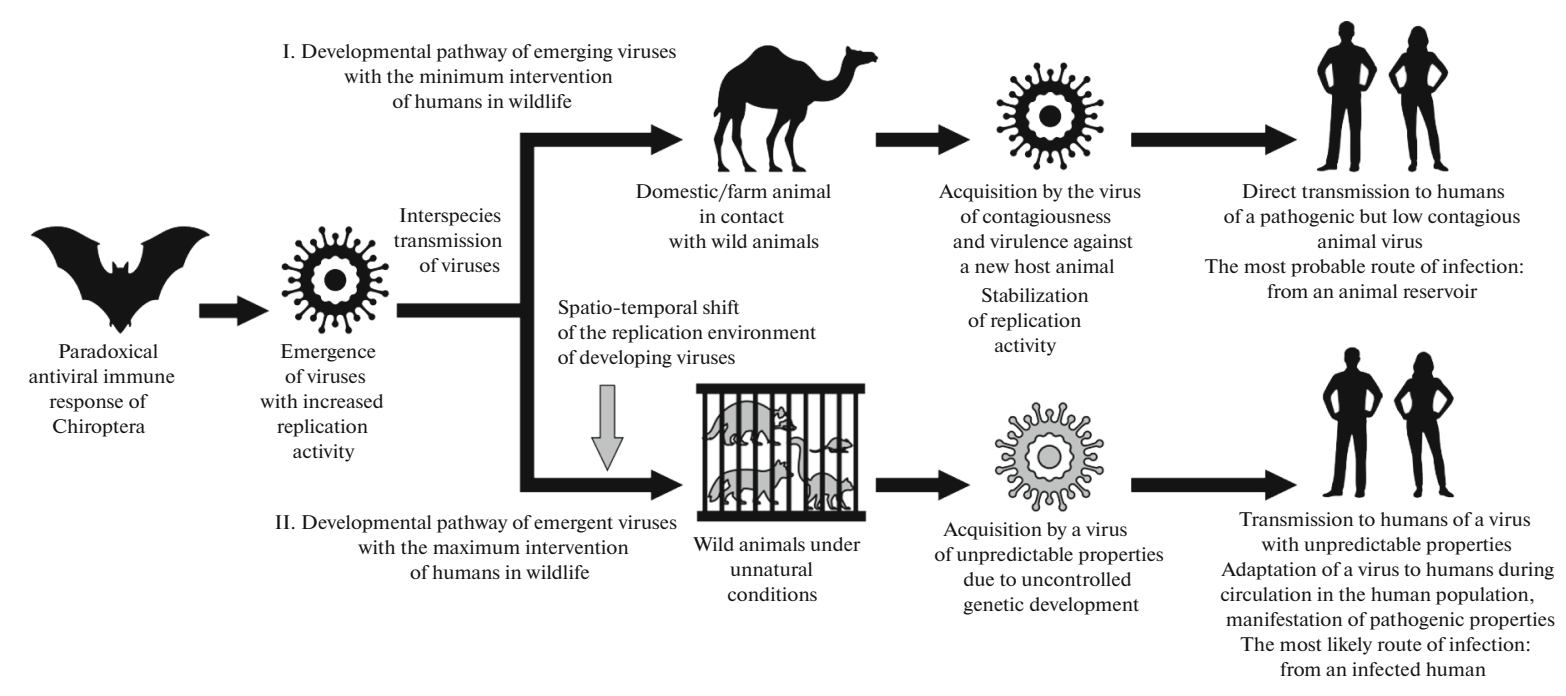

Fig. 1. Two scenarios of the emergence of coronavirus infections: I, the development of MERS-CoV; II, the development of SARS-CoV and probably SARS-CoV-2.

mal, which prevents the reduction of its ability to overcome interspecies barriers and stabilization of the replication activity acquired due to Chiroptera. This allows $\mathrm{CoV}$ with unknown pathogenic properties to adapt quickly to a new host (human) organism and to acquire stable intraspecific contagiousness. The examples of this scenario are SARS-CoV and probably SARS-CoV-2, because they are closer to the potential precursor viruses of Chiroptera (95 and 96.3\%), their probable intermediate hosts were kept in Chinese animal markets (civets, raccoon dogs (SARS-CoV); Javan pangolin Manis javanica (SARS-CoV-2)), and their contagiousness among humans is noticeably higher compared to MERS-CoV, while the lethality is lower (9.5 and 2.3\%, respectively) (Lam et al., 2020; Yang et al., 2020).

The most efficient measure for preventing future outbreaks, in our opinion, is the bioveterinary and sanitary control of animal markets, and not only in China. Elimination of the conditions that provide a favorable background for unpredictable evolution of pathogenic $\mathrm{CoV}$ will provide more resources for studying stable transmission chains such as MERS-CoV and the methods of their control.

One more potential and effective method to prevent distribution of coronaviral infections is application of probiotic bacteria as they can inhibit viral replication activity and exert an antiviral effect by producing lactic acid, hydrogen peroxide, and bacteriocins (Sekar et al., 2016; Kanmani et al., 2018; Abdelhamid et al., 2019). In addition, the study of feline microbiota has shown that bacteria of the genus Lactobacillus can have an antagonistic effect on the feline intestinal $\mathrm{CoV}$ (Mingmongkolchai and Panbangred, 2018), suggesting the necessity of large-scale studies on possible modulation of animal health with probiotics. The agricultural applications of probiotics will make it pos- sible to prevent coronaviral infections emerging from cattle and other animals as potential reservoirs of infection and to reduce the probability of repeating the first variant of the proposed scenario.

\section{CONCLUSIONS}

Animal coronaviruses are epidemiologically dangerous due to their enhanced interspecies transmission capabilities and replication and recombination activities. Homologous coronaviruses with common properties have been detected in many animal species, which is indicative of their continuous evolutionary development. However, humans make the maximum contribution to formation of conditions for new emergent coronaviruses by intervening in wildlife, removing wild animals from their habitats, providing contacts between species that never encounter each other under natural conditions, and thereby forming new routes for transmission of coronaviruses between wild animals and humans.

At present, there is no evidence for the fact that companion animals can be carriers of the new coronavirus infection. However, it is not improbable that representatives of the family Felidae might be a biological dead end in the global routes of SARS-CoV-2 transmission. This subject requires large-scale cohort clinical studies.

Similar to the singularity existing before the Bing Bang, humans intervening in wildlife make different species of animals and their viruses to collide in a single spatio-temporal point, thereby provoking the emergence of a biosphere with unpredictable consequences. 


\section{FUNDING}

This work was supported by the Government of the Russian Federation, agreement no. 075-15-2019-1880.

\section{COMPLIANCE WITH ETHICAL STANDARDS}

The authors declare that they have no conflict of interest. This article does not contain any studies involving animals or human participants performed by any of the authors.

\section{REFERENCES}

Abdelhamid, A.G., El-Masry, S.S., and El-Dougdoug, N.K., Probiotic Lactobacillus and Bifidobacterium strains possess safety characteristics, antiviral activities and host adherence factors revealed by genome mining, EPMA J., 2019, vol. 10, no. 4 , pp. $337-350$.

https://doi.org/10.1007/s13167-019-00184-z

Adney, D.R., van Doremalen, N., Brown, V.R., Bushmaker, T., Scott, D., de Wit, E., Bowen, R.A., and Munster, V.J., Replication and shedding of MERS-CoV in upper respiratory tract of inoculated dromedary camels, Emerg. Infect. Dis., 2014, vol. 20, no. 12, pp. 1999-2005. https://doi.org/10.3201/eid2012.141280

Agrawal, A.S., Garron, T., Tao, X., Peng, B.H., Wakamiya, M., Chan, T.S., Couch, R.B., and Tseng, C.T., Generation of a transgenic mouse model of middle east respiratory syndrome coronavirus infection and disease, J. Virol., 2015, vol. 89 , no. 7 , pp. $3659-3670$.

https://dx.doi.org/10.1128\%2FJVI.03427-14

Ahn, M., Anderson, D.E., Zhang, Q., Tan, C.W., Lim, B.L., Luko, K., Wen, M., Chia, W.N., Mani, S., Wang, L.C., Ng, J.H.J., Sobota, R.M., Dutertre, C.A., Ginhoux, F., Shi, Z.L., Irving, A.T., and Wang, L.F., Dampened NLRP3mediated inflammation in bats and implications for a special viral reservoir host, Nat. Microbiol., 2019, vol. 4, no. 5, pp. 789-799.

https://dx.doi.org/10.1038\%2Fs41564-019-0371-3

Barlough, J.E., Stoddart, C.A., Sorresso, G.P., Jacobson, R.H., and Scott, F.W., Experimental inoculation of cats with canine coronavirus and subsequent challenge with feline infectious peritonitis virus, Lab. Anim. Sci., 1984, vol. 34, no. 6, pp. 592-597.

Barlough, J.E., Johnson-Lussenburg, C.M., Stoddart, C.A., Jacobson, R.H., and Scott, F.W., Experimental inoculation of cats with human coronavirus $229 \mathrm{E}$ and subsequent challenge with feline infectious peritonitis virus, Can. J. Comp. Med., 1985, vol. 49, no. 3, pp. 303-307.

Binn, L.N., Lazar, E.C., Keenan, K.P., Huxsoll, D.L., Marchwicki, R.H., and Strano, A.J., Recovery and characterization of a coronavirus from military dogs with diarrhea, Proc. Annu. Meet. US Anim. Health. Assoc., 1974, vol. 78, pp. 359-366.

van Boheemen, S., de Graaf, M., Lauber, C., Bestebroer, T.M., Raj, V.S., Zaki, A.M., Osterhaus, A.D., Haagmans, B.L., Gorbalenya, A.E., Snijder, E.J., and Fouchier, R.A., Genomic characterization of a newly discovered coronavirus associated with acute respiratory distress syndrome in humans, $m$ Bio, 2012, vol. 3, no. 6. e00473-12.

https://dx.doi.org/10.1128\%2FmBio.00473-12

van den Brand, J.M., Haagmans, B.L., Leijten, L., van Riel, D., Martina, B.E., Osterhaus, A.D., and Kuiken, T., Pa- thology of experimental sars coronavirus infection in cats and ferrets, Vet. Pathol., 2008, vol. 45, no. 4, pp. 551-562. https://doi.org/10.1354/vp.45-4-551

Brook, C.E., Boots, M., Chandran, K., Dobson, A.P., Drosten, C., Graham, A.L., Grenfell, B.T., Müller, M.A., $\mathrm{Ng}$, M., Wang, L.F., and van Leeuwen, A., Accelerated viral dynamics in bat cell lines, with implications for zoonotic emergence, Elife, 2020, vol. 9. e48401.

https://dx.doi.org/10.7554\%2FeLife.48401

Carman, P.S. and Hazlett, M.J., Bovine coronavirus infection in Ontario 1990-1991, Can. Vet. J., 1992, vol. 33, no. 12 , pp. 812-814.

Chu, H., Chan, J.F.W., Yuen, T.T.T., Shuai, H., Yuan, S., Wang, Y., Hu, B., Yip, C.C.Y., Tsang, J.O.L., Huang, X., Chai, Y., Yang, D., Hou, Y., Chik, K.K.H., Zhang, X., Fung, A.Y.F., Tsoi, H.W., Cai, J.P., Chan, W.M., Ip, J.D., Chu, A.W.H., Zhou, J., Lung, D.C., Kok, K.H., To, K.K.W., Tsang, O.T.Y., Chan, K.H., and Yuen, K.Y., Comparative tropism, replication kinetics, and cell damage profiling of SARS-CoV-2 and SARS-CoV with implications for clinical manifestations, transmissibility, and laboratory studies of COVID-19: an observational study, Lancet Microbe, 2020, vol. 1, no. 1, pp. e14-e23.

https://dx.doi.org/10.1016\%2FS2666-5247(20)30004-5

Collins, S.E. and Mossman, K.L., Danger, diversity and priming in innate antiviral immunity, Cytokine Growth Factor Rev., 2014, vol. 25, no. 5, pp. 525-531.

https://doi.org/10.1016/j.cytogfr.2014.07.002

Corman, V.M., Baldwin, H.J., Tateno, A.F., Zerbinati, R.M., Annan, A., Owusu, M., Nkrumah, E.E., Maganga, G.D., Oppong, S., Adu-Sarkodie, Y., Vallo, P., Silva, FilhoL.V., Leroy, E.M., Thiel, V., van der Hoek, L., Poon, L.L., Tschapka, M., Drosten, C., and Drexler, J.F., Evidence for an ancestral association of human coronavirus $229 \mathrm{E}$ with bats, J. Virol., 2015, vol. 89, no. 23, pp. 11858-11870. https://dx.doi.org/10.1128\%2FJVI.01755-15

Corman, V.M., Muth, D., Niemeyer, D., and Drosten, C., Hosts and sources of endemic human coronaviruses, $A d v$. Virus. Res., 2018, vol. 100, pp. 163-188.

https://dx.doi.org/10.1016\%2Fbs.aivir.2018.01.001

Crossley, B.M., Barr, B.C., Magdesian, K.G., Ing, M., Mora, D., Jensen, D., Loretti, A.P., McConnell, T., and Mock, R., Identification of a novel coronavirus possibly associated with acute respiratory syndrome in alpacas (Vicugna pacos) in California, 2007, J. Vet. Diagn. Invest., 2010, vol. 22, no. 1, pp. 94-97.

https://doi.org/10.1177/104063871002200118

Crossley, B.M., Mock, R.E., Callison, S.A., and Hietala, S.K., Identification and characterization of a novel alpaca respiratory coronavirus most closely related to the human coronavirus 229E, Viruses, 2012, vol. 4, no. 12, pp. 3689-3700. https://dx.doi.org/10.3390\%2Fv4123689

Cui, J., Li, F., and Shi, Z.L., Origin and evolution of pathogenic coronaviruses, Nat. Rev. Microbiol., 2019, vol. 17, no. 3, pp. $181-192$.

https://dx.doi.org/10.1038\%2Fs41579-018-0118-9

Decaro, N. and Buonavoglia, C., An update on canine coronaviruses: viral evolution and pathobiology, Vet. Microbiol., 2008, vol. 132, nos. 3-4, pp. 221-234. https://dx.doi.org/10.1016\%2Fj.vetmic.2008.06.007

Decaro, N. and Buonavoglia, C., Canine coronavirus: not only an enteric pathogen, Vet. Clin. North Am. Small Anim. 
Pract., 2011, vol. 41, no. 6, pp. 1121-1132.

https://doi.org/10.1016/j.cvsm.2011.07.005

Decaro, N., Campolo, M., Desario, C., Cirone, F., D’Abramo, M., Lorusso, E., Greco, G., Mari, V., Colaianni, M.L., Elia, G., Martella, V., and Buonavoglia, C., Respiratory disease associated with bovine coronavirus infection in cattle herds in Southern Italy, J. Vet. Diagn. Invest., 2008, vol. 20 , no. 1 , pp. $28-32$.

\section{https://doi.org/10.1177/104063870802000105}

Decaro, N., Mari, V., Campolo, M., Lorusso, A., Camero, M., Elia, G., Martella, V., Cordioli, P., Enjuanes, L., and Buonavoglia, C., Recombinant canine coronaviruses related to transmissible gastroenteritis virus of swine are circulating in dogs, J. Virol., 2009, vol. 83, no. 3, pp. 1532-1537. https://dx.doi.org/10.1128\%2FJVI.01937-08

Decaro, N., Mari, V., Elia, G., Addie, D.D., Camero, M., Lucente, M.S., Martella, V., and Buonavoglia, C., Recombinant canine coronaviruses in dogs, Europe, Emerg. Infect. Dis., 2010a, vol. 16, no. 1, pp. 41-47. https://dx.doi.org/10.3201\%2Feid1601.090726

Decaro, N., Elia, G., Martella, V., Campolo, M., Mari, V., Desario, C., Lucente, M.S., Lorusso, E., Kanellos, T., Gibbons, R.H., and Buonavoglia, C., Immunity after natural exposure to enteric canine coronavirus does not provide complete protection against infection with the new pantropic CB/05 strain, Vaccine, 2010b, vol. 28, no. 3, pp. 724-729. https://dx.doi.org/10.1016\%2Fj.vaccine.2009.10.077

DiVincenti, L., Jr. and Rehrig, A.N., The social nature of European rabbits (Oryctolagus cuniculus), J. Am. Assoc. Lab. Anim. Sci., 2016, vol. 55, no. 6, pp. 729-736.

Drexler, J.F., Corman, V.M., Müller, M.A., Maganga, G.D., Vallo, P., Binger, T., Gloza-Rausch, F., Cottontail, V.M., Rasche, A., Yordanov, S., Seebens, A., Knörnschild M., Oppong, S., Adu Sarkodie, Y., Pongombo, C., Lukashev, A.N., Schmidt-Chanasit, J., Stöcker, A., Carneiro, A.J., Erbar, S., Maisner, A., Fronhoffs, F., Buettner, R., Kalko, E.K., Kruppa, T., Franke, C.R., Kallies, R., Yandoko, E.R., Herrler, G., Reusken, C., Hassanin, A., Krüger, D.H., Matthee, S., Ulrich, R.G., Leroy, E.M., and Drosten, C., Bats host major mammalian paramyxoviruses, Nat. Commun., 2012, vol. 3, p. 796.

https://dx.doi.org/10.1038\%2Fncomms1796

Erles, K. and Brownlie, J., Canine respiratory coronavirus: an emerging pathogen in the canine infectious respiratory disease complex, Vet. Clin. North Am. Small Anim. Pract., 2008, vol. 38, no. 4, pp. 815-825.

https://dx.doi.org/10.1016\%2Fj.cvsm.2008.02.008

Erles, K., Shiu, K.B., and Brownlie, J., Isolation and sequence analysis of canine respiratory coronavirus, Virus. Res, 2007, vol. 124, nos. 1-2, pp. 78-87.

https://dx.doi.org/10.1016\%2Fj.virusres.2006.10.004

Felten, S. and Hartmann, K., Diagnosis of feline infectious peritonitis: a review of the current literature, Viruses, 2019, vol. 11 , no. 11, p. 1068.

https://dx.doi.org/10.3390\%2Fv11111068

Forbes, K.M., Webala, P.W., Jääskeläinen, A.J., Abdurahman, S., Ogola, J., Masika, M.M., Kivistö, I., Alburkat, H., Plyusnin, I., Levanov, L., Korhonen, E.M., Huhtamo, E., Mwaengo, D., Smura, T., Mirazimi, A., Anzala, O., Vapalahti, O., and Sironen, T., Bombali virus in Mops condylurus bat, Kenya, Emerg. Infect. Dis., 2019, vol. 25, no. 5, pp. 955-957.

https://dx.doi.org/10.3201\%2Feid2505.181666
Goldstein, T., Anthony, S.J., Gbakima, A., Bird, B.H., Bangura, J., Tremeau-Bravard, A., Belaganahalli, M.N., Wells, H.L., Dhanota, J.K., Liang, E., Grodus, M., Jangra, R.K., DeJesus, V.A., Lasso, G., Smith, B.R., Jambai, A., Kamara, B.O., Kamara, S., Bangura, W., Monagin, C., Shapira, S., Johnson, C.K., Saylors, K., Rubin, E.M., Chandran, K., Lipkin, W.I., and Mazet, J.A.K., The discovery of Bombali virus adds further support for bats as hosts of ebolaviruses, Nat. Microbiol., 2018, vol. 3, no. 10, pp. 1084-1089.

https://dx.doi.org/10.1038\%2Fs41564-018-0227-2

Gong, S.R. and Bao, L.L., The battle against SARS and MERS coronaviruses: reservoirs and animal models, Anim. Model Exp. Med., 2018, vol. 1, no. 2, pp. 125-133. https://dx.doi.org/10.1002\%2Fame2.12017

Gorbalenya, A.E., Baker, S.C., Baric, R.S., de Groot, R.J., Drosten, C., Gulyaeva, A.A., Haagmans, B.L., Lauber, C., Leontovich, A.M., Neuman, B.W., Penzar, D., Perlman, S., Poon, L.L.M., Samborskiy, D.V., Sidorov, I.A., Sola, I., and Ziebuhr, J., The species Severe acute respiratory syndrome-related coronavirus: classifying 2019-nCoV and naming it SARS-CoV-2, Nat. Microbiol., 2020, vol. 5, no. 4, pp. 536-544.

https://doi.org/10.1038/s41564-020-0695-Z

Guan, Y., Zheng, B.J., He, Y.Q., Liu, X.L., Zhuang, Z.X., Cheung, C.L., Luo, S.W., Li, P.H., Zhang, L.J., Guan, Y.J., Butt, K.M., Wong, K.L., Chan, K.W., Lim, W., Shortridge, K.F., Yuen, K.Y., Peiris, J.S., and Poon, L.L., Isolation and characterization of viruses related to the SARS coronavirus from animals in southern china, Science, 2003, vol. 302, no. 5643, pp. 276-278.

https://doi.org/10.1126/science.1087139

Guo, H., Guo, A., Wang, C., Yan, B., Lu, H., and Chen, H., Expression of feline angiotensin converting enzyme 2 and its interaction with SARS-CoV S1 protein, Res. Vet. Sci., 2008, vol. 84, no. 3, pp. 494-496.

https://dx.doi.org/10.1016\%2Fj.rvsc.2007.05.011

Haagmans, B.L., Brand, J.M., Provacia, L.B., Raj, V.S., Stittelaar, K.J., Getu, S., de Waal, L., Bestebroer, T.M., van Amerongen, G., Verjans, G.M., Fouchier, R.A., Smits, S.L., Kuiken, T., and Osterhaus, A.D., Asymptomatic Middle East respiratory syndrome coronavirus infection in rabbits, J. Virol., 2015, vol. 89, no. 11, pp. 6131-6135. https://dx.doi.org/10.1128\%2FJVI.00661-15

Hawkins, J.A., Kaczmarek, M.E., Müller, M.A., Drosten, C., Press, W.H., and Sawyer, S.L., A metaanalysis of bat phylogenetics and positive selection based on genomes and transcriptomes from 18 species, Proc. Natl. Acad. Sci. U. S. A., 2019, vol. 116, no. 23, pp. 11351-11360.

https://dx.doi.org/10.1073\%2Fpnas.1814995116

Heckert, R.A., Saif, L.J., Hoblet, K.H., and Agnes, A.G., A longitudinal study of bovine coronavirus enteric and respiratory infections in dairy calves in two herds in Ohio, Vet. Microbiol., 1990, vol. 22, nos. 2-3, pp. 187-201. https://dx.doi.org/10.1016\%2F0378-1135(90)90106-6

Jaimes, J.A. and Whittaker, G.R., Feline coronavirus: insights into viral pathogenesis based on the spike protein structure and function, Virology, 2018, vol. 517, pp. 108-121.

https://dx.doi.org/10.1016\%2Fj.virol.2017.12.027

Ji, W., Wang, W., Zhao, X., Zai, J., and Li, X., Cross-species transmission of the newly identified coronavirus 2019nCoV, J. Med. Virol., 2020, vol. 92, no. 4, pp. 433-440. https://dx.doi.org/10.1002\%2Fjmv.25682 
Kaneshima, T., Hohdatsu, T., Hagino, R., Hosoya, S., Nojiri, Y., Murata, M., Takano, T., Tanabe, M., Tsunemitsu, H., and Koyama, H., The infectivity and pathogenicity of a group 2 bovine coronavirus in pups, J. Vet. Med. Sci., 2007, vol. 69 , no. 3 , pp. $301-303$.

https://doi.org/10.1292/jvms.69.301

Kanmani, P., Albarracin, L., Kobayashi, H., Hebert, E.M., Saavedra, L., Komatsu, R., Gatica, B., Miyazaki, A., Ikeda-Ohtsubo, W., Suda, Y., Aso, H., Egusa, S., Mishima, T., Salas-Burgos, A., Takahashi, H., Villena, J., and Kitazawa, H., Genomic characterization of Lactobacillus delbrueckii TUA4408L and evaluation of the antiviral activities of its extracellular polysaccharides in porcine intestinal epithelial cells, Front. Immunol., 2018, vol. 9, p. 2178.

https://doi.org/10.3389/fimmu.2018.02178

Lam, T.T., Jia, N., Zhang, Y.W., Shum, M.H., Jiang, J.F., Zhu, H.C., Tong, Y.G., Shi, Y.X., Ni, X.B., Liao, Y.S., Li, W.J., Jiang, B.G., Wei, W., Yuan, T.T., Zheng, K., Cui, X.M., Li, J., Pei, G.Q., Qiang, X., Cheung, W.Y., Li, L.F., Sun, F.F., Qin, S., Huang, J.C., Leung, G.M., Holmes, E.C., $\mathrm{Hu}$, Y.L., Guan, Y., and Cao, W.C., Identifying SARS$\mathrm{CoV}-2$-related coronaviruses in Malayan pangolins, $\mathrm{Na}$ ture, 2020, vol. 583, no. 7815, pp. 282-285.

https://doi.org/10.1038/s41586-020-2169-0

Lau, S.K., Woo, P.C., Li, K.S., Huang, Y., Tsoi, H.W., Wong, B.H., Wong, S.S., Leung, S.Y., Chan, K.H., and Yuen, K.Y., Severe acute respiratory syndrome coronavirus-like virus in Chinese horseshoe bats, Proc. Natl. Acad. Sci. U. S. A., 2005, vol. 102, no. 39, pp. 14040-14045. https://dx.doi.org/10.1073\%2Fpnas.0506735102

Lau, S.K.P., Zhang, L., Luk, H.K.H., Xiong, L., Peng, X., Li, K.S.M., He, X., Zhao, P.S., Fan, R.Y.Y., Wong, A.C.P., Ahmed, S.S., Cai, J.P., Chan, J.F.W., Sun, Y., Jin, D., Chen, H., Lau, T.C.K., Kok, R.K.H., Li, W., Yuen, K.Y., and Woo, P.C.Y., Receptor usage of a novel bat lineage C betacoronavirus reveals evolution of Middle East respiratory syndrome-related coronavirus spike proteins for human dipeptidyl peptidase 4 binding, J. Infect. Dis., 2018, vol. 218, no. 2, pp. 197-207.

https://dx.doi.org/10.1093\%2Finfdis\%2Fjiy018

Li, W., Shi, Z., Yu, M., Ren, W., Smith, C., Epstein, J.H., Wang, H., Crameri, G., Hu, Z., Zhang, H., Zhang, J., McEachern, J., Field, H., Daszak, P., Eaton, B.T., Zhang, S., and Wang, L.F., Bats are natural reservoirs of SARS-like coronaviruses, Science, 2005, vol. 310, no. 5748, pp. 676679.

https://doi.org/10.1126/science.1118391

Li, X., Luk, H.K.H., Lau, S.K.P., and Woo, P.C.Y., Human coronaviruses: general features, Ref. Mod. Biomed. Sci., 2019, p. B978-0-12-801238-3.95704-0. https://dx.doi.org/10.1016\%2FB978-0-12-801238-3.95704-0

Lu, S., Wang, Y., Chen, Y., Wu, B., Qin, K., Zhao, J., Lou, Y., and Tan, W., Discovery of a novel canine respiratory coronavirus support genetic recombination among betacoronavirus1, Virus. Res., 2017, vol. 237, pp. 7-13. https://dx.doi.org/10.1016\%2Fj.virusres.2017.05.006

Lu, R., Zhao, X., Li, J., Niu, P., Yang, B., Wu, H., Wang, W., Song, H., Huang, B., Zhu, N., Bi, Y., Ma, X., Zhan, F., Wang, L., Hu, T., Zhou, H., Hu, Z., Zhou, W., Zhao, L., Chen, J., Meng, Y., Wang, J., Lin, Y., Yuan, J., Xie, Z., Ma, J., Liu, W.J., Wang, D., Xu, W., Holmes, E.C., Gao, G.F., Wu, G., Chen, W., Shi, W., and Tan, W., Genomic characterisation and epidemiology of 2019 novel coronavirus: im- plications for virus origins and receptor binding, Lancet, 2020 , vol. 395 , no. 10224 , pp. 565-574.

https://dx.doi.org/10.1016\%2FS0140-6736(20)30251-8

Luo, C.M., Wang, N., Yang, X.L., Liu, H.Z., Zhang, W., Li, B., Hu, B., Peng, C., Geng, Q.B., Zhu, G.J., Li, F., and Shi, Z.L., Discovery of novel bat coronaviruses in South China that use the same receptor as middle east respiratory syndrome coronavirus, J. Virol., 2018, vol. 92, no. 13, pp. e00116-00118.

https://dx.doi.org/10.1128\%2FJVI.00116-18

Martina, B.E., Haagmans, B.L., Kuiken, T., Fouchier, R.A., Rimmelzwaan, G.F., Van Amerongen, G., Peiris, J.S., Lim, W., and Osterhaus, A.D., Virology: SARS virus infection of cats and ferrets, Nature, 2003, vol. 425, no. 6961, p. 915 .

https://dx.doi.org/10.1038\%2F425915a

Milewska, A., Nowak, P., Owczarek, K., Szczepanski, A., Zarebski, M., Hoang, A., Berniak, K., Wojarski, J., Zeglen, S., Baster, Z., Rajfur, Z., and Pyrc, K., Entry of human coronavirus nl63 into the cell, J. Virol., 2018, vol. 92, no. 3, pp. e01933-01917.

https://dx.doi.org/10.1128\%2FJVI.01933-17

Milne-Price, S., Miazgowicz, K.L., and Munster, V.J., The emergence of the Middle East respiratory syndrome coronavirus, Pathog. Dis., 2014, vol. 71, no. 2, pp. 121-136. https://dx.doi.org/10.1111\%2F2049-632X.12166

Mingmongkolchai, S. and Panbangred, W., Bacillus probiotics: an alternative to antibiotics for livestock production, J. Appl. Microbiol., 2018, vol. 124, no. 6, pp. 1334-1346. https://doi.org/10.1111/jam.13690

Mohd, H.A., Al-Tawfiq, J.A., and Memish, Z.A., Middle East respiratory syndrome coronavirus (MERS-CoV) origin and animal reservoir, Virol. J., 2016, vol. 13, p. 87. https://dx.doi.org/10.1186\%2Fs12985-016-0544-0

Ogando, N.S., Ferron, F., Decroly, E., Canard, B., Posthuma, C.C., and Snijder, E.J., The curious case of the nidovirus exoribonuclease: its role in RNA synthesis and replication fidelity, Front. Microbiol., 2019, vol. 10, p. 1813. https://dx.doi.org/10.3389\%2Ffmicb.2019.01813

Omrani, A.S., Al-Tawfiq, J.A., and Memish, Z.A., Middle East respiratory syndrome coronavirus (MERS-CoV): animal to human interaction, Pathog. Glob. Health, 2015, vol. 109 , no. 8 , pp. $354-362$.

https://dx.doi.org/10.1080\%2F20477724.2015.1122852

Pavlovich, S.S., Lovett, S.P., Koroleva, G., Guito, J.C., Arnold, C.E., Nagle, E.R., Kulcsar, K., Lee, A., ThibaudNissen, F., Hume, A.J., Mühlberger, E., Uebelhoer, L.S., Towner, J.S., Rabadan, R., Sanchez-Lockhart, M., Kepler, T.B., and Palacios, G., The Egyptian rousette genome reveals unexpected features of bat antiviral immunity, Cell, 2018, vol. 173 , no. 5 , pp. $1098-1110$. e18.

https://dx.doi.org/10.1016\%2Fj.cell.2018.03.070

Perlman, S. and Netland, J., Coronaviruses post-SARS: update on replication and pathogenesis, Nat. Rev. Microbiol., 2009, vol. 7, pp. 439-450.

https://doi.org/10.1038/nrmicro2147

Petrosillo, N., Viceconte, G., Ergonul, O., Ippolito, G., and Petersen, E., COVID-19, SARS and MERS: are they closely related?, Clin. Microbiol. Infect., 2020, vol. 26, no. 6, pp. 729-734.

https://dx.doi.org/10.1016\%2Fj.cmi.2020.03.026 
Le Poder, S., Feline and canine coronaviruses: common genetic and pathobiological features, Adv. Virol., 2011, vol. 2011, p. 609465.

https://dx.doi.org/10.1155\%2F2011\%2F609465

Raj, V.S., Smits, S.L., Provacia, L.B., Brand, J.M., Wiersma, L., Ouwendijk, W.J., Bestebroer, T.M., Spronken, M.I., van Amerongen, G., Rottier, P.J., Fouchier, R.A., Bosch, B.J., Osterhaus, A.D., and Haagmans, B.L., Adenosine deaminase acts as a natural antagonist for dipeptidyl peptidase 4-mediated entry of the Middle East respiratory syndrome coronavirus, J. Virol., 2014a, vol. 88, no. 3, pp. 1834-1838. https://dx.doi.org/10.1128\%2FJVI.02935-13

Raj, V.S., Farag, E.A., Reusken, C.B., Lamers, M.M., Pas, S.D., Voermans, J., Smits, S.L., Osterhaus, A.D., AlMawlawi, N., Al-Romaihi, H.E., AlHajri, M.M., ElSayed, A.M., Mohran, K.A., Ghobashy, H., Alhajri, F., AlThani, M., Al-Marri, S.A., El-Maghraby, M.M., Koopmans, M.P., and Haagmans, B.L., Isolation of MERS coronavirus from a dromedary camel, Qatar, 2014, Emerg. Infect. Dis., 2014b, vol. 20, no. 8, pp. 1339-1342.

https://dx.doi.org/10.3201\%2Feid2008.140663

Sabir, J.S., Lam, T.T., Ahmed, M.M., Li, L., Shen, Y., Abo-Aba, S.E., Qureshi, M.I., Abu-Zeid, M., Zhang, Y., Khiyami, M.A., Alharbi, N.S., Hajrah, N.H., Sabir, M.J., Mutwakil, M.H., Kabli, S.A., Alsulaimany, F.A., Obaid, A.Y., Zhou, B., Smith, D.K., Holmes, E.C., Zhu, H., and Guan, Y., Co-circulation of three camel coronavirus species and recombination of MERS-CoVs in Saudi Arabia, Science, 2016, vol. 351, no. 6268, pp. 81-84.

https://doi.org/10.1126/science.aac8608

Samara, E.M. and Abdoun, K.A., Concerns about misinterpretation of recent scientific data implicating dromedary camels in epidemiology of Middle East respiratory syndrome (MERS), mBio, 2014, vol. 5, no. 4, pp. e0143001414.

https://dx.doi.org/10.1128\%2FmBio.01430-14

Sazmand, A., Joachim, A., and Otranto, D., Zoonotic parasites of dromedary camels: so important, so ignored, Parasit. Vectors, 2019, vol. 12, no. 1, p. 610. https://dx.doi.org/10.1186\%2Fs13071-019-3863-3

Sekar, A., Packyam, M., and Kim, K., Growth enhancement of shrimp and reduction of shrimp infection by Vibrio parahaemolyticus and white spot syndrome virus with dietary administration of Bacillus sp. Mk22, Microb. Biotechnol. Lett., 2016, vol. 44, pp. 261-267.

https://doi.org/10.4014/mbl.1605.05001

Shi, W., Li, J., Zhou, H., and Gao, G.F., Pathogen genomic surveillance elucidates the origins, transmission and evolution of emerging viral agents in China, Sci. China Life Sci., 2017, vol. 60, no. 12, pp. 1317-1330.

https://dx.doi.org/10.1007\%2Fs11427-017-9211-0

Shi, J., Wen, Z., Zhong, G., Yang, H., Wang, C., Huang, B., Liu, R., He, X., Shuai, L., Sun, Z., Zhao, Y., Liu, P., Liang, L., Cui, P., Wang, J., Zhang, X., Guan, Y., Tan, W., Wu, G., Chen, H., and Bu, Z., Susceptibility of ferrets, cats, dogs, and other domesticated animals to SARS-coronavirus 2, Science, 2020 , p. eabb7015.

https://dx.doi.org/10.1126\%2Fscience.abb7015

So, R.T.Y., Chu, D.K.W., Miguel, E., Perera, R.A.P.M., Oladipo, J.O., Fassi-Fihri, O., Aylet, G., Ko, R.L.W., Zhou, Z., Cheng, M.S., Kuranga, S.A., Roger, F.L., Chevalier, V., Webby, R.J., Woo, P.C.Y., Poon, L.L.M., and Peiris, M., Diversity of dromedary camel coronavirus
HKU23 in African camels revealed multiple recombination events among closely related betacoronaviruses of the subgenus Embecovirus, J. Virol., 2019, vol. 93, no. 23, pp. 1-18. https://doi.org/10.1128/JVI.01236-19

Sun, J., He, W.T., Wang, L., Lai, A., Ji, X., Zhai, X., Li, G., Suchard, M.A., Tian, J., Zhou, J., Veit, M., and Su, S., COVID-19: epidemiology, evolution, and cross-disciplinary perspectives, Trends. Mol. Med., 2020, vol. 26, no. 5, pp. 483-495.

https://dx.doi.org/10.1016\%2Fj.molmed.2020.02.008

Tang, X., Wu, C., Li, X., Song, Y., Yao, X., Wu, X., Duan, Y., Zhang, H., Wang, Y., Qian, Z., Cui, J., and Lu, J., On the origin and continuing evolution of SARS-CoV-2, Nat. Sci. Rev., 2020. nwaa036.

https://doi.org/10.1093/nsr/nwaa036

Temmam, S., Barbarino, A., Maso, D., Behillil, S., Enouf, V., Huon, C., Jaraud, A., Chevallier, L., Backovic, M., Perot, P., Verwaerde, P., Tiret, L., van der Werf, S., and Eloit, M., Absence of SARS-CoV-2 infection in cats and dogs in close contact with a cluster of COVID-19 patients in a veterinary campus, bioRxiv, 2020.

https://doi.org/10.1101/2020.04.07.029090

Tseng, C.T., Sbrana, E., Iwata-Yoshikawa, N., Newman, P.C., Garron, T., Atmar, R.L., Peters, C.J., and Couch, R.B., Immunization with SARS coronavirus vaccines leads to pulmonary immunopathology on challenge with the SARS virus, PLoS One, 2012, vol. 7, no. 4. e35421.

https://doi.org/10.1371/journal.pone.0035421

Tu, C., Crameri, G., Kong, X., Chen, J., Sun, Y., Yu, M., Xiang, H., Xia, X., Liu, S., Ren, T., Yu, Y., Eaton, B.T., Xuan, H., and Wang, L.F., Antibodies to SARS coronavirus in civets, Emerg. Infect. Dis., 2004, vol. 10, no. 12, pp. 22442248.

https://dx.doi.org/10.3201\%2Feid1012.040520

Vijgen, L., Keyaerts, E., Moës, E., Thoelen, I., Wollants, E., Lemey, P., Vandamme, A.M., and Van Ranst, M., Complete genomic sequence of human coronavirus OC43: molecular clock analysis suggests a relatively recent zoonotic coronavirus transmission event, J. Virol., 2005, vol. 79, no. 3, pp. 1595-1604.

https://dx.doi.org/10.1128\%2FJVI.79.3.1595-1604.2005

Vijgen, L., Keyaerts, E., Lemey, P., Maes, P., Van Reeth, K., Nauwynck, H., Pensaert, M., and Van Ranst, M., Evolutionary history of the closely related group 2 coronaviruses: porcine hemagglutinating encephalomyelitis virus, bovine coronavirus, and human coronavirus OC43, J. Virol., 2006, vol. 80 , no. 14 , pp. $7270-7274$.

https://dx.doi.org/10.1128\%2FJVI.02675-05

Wicker, L.V., Canfield, P.J., and Higgins, D.P., Potential pathogens reported in species of the family Viverridae and their implications for human and animal health, Zoonoses Public Health, 2017, vol. 64, no. 2, pp. 75-93.

https://doi.org/10.1111/zph.12290

Widagdo, W., Sooksawasdi, Na., Ayudhya, S., Hundie, G.B., and Haagmans, B.L., Host determinants of MERS-CoV transmission and pathogenesis, Viruses, 2019, vol. 11, no. 3, p. E280.

https://doi.org/10.3390/v11030280

Wong, A.C.P., Li, X., Lau, S.K.P., and Woo, P.C.Y., Global epidemiology of bat coronaviruses, Viruses, 2019, vol. 11, no. 2 , p. 174.

https://dx.doi.org/10.3390\%2Fv11020174 
Woo, P.C., Lau, S.K., Wernery, U., Wong, E.Y., Tsang, A.K., Johnson, B., Yip, C.C., Lau, C.C., Sivakumar, S., Cai, J.P., Fan, R.Y., Chan, K.H., Mareena, R., and Yuen, K.Y., Novel betacoronavirus in dromedaries of the Middle East, 2013, Emerg. Infect. Dis., 2014, vol. 20, no. 4, pp. 560-572. https://dx.doi.org/10.3201\%2Feid2004.131769

Woo, P.C., Lau, S.K., Fan, R.Y., Lau, C.C., Wong, E.Y., Joseph, S., Tsang, A.K., Wernery, R., Yip, C.C., Tsang, C.C., Wernery, U., and Yuen, K.Y., Isolation and characterization of dromedary camel coronavirus UAE-HKU23 from dromedaries of the Middle East: minimal serological crossreactivity between MERS coronavirus and dromedary camel coronavirus UAE-HKU23, Int. J. Mol. Sci., 2016, vol. 17, no. 5 , p. 691.

https://dx.doi.org/10.3390\%2Fijms 17050691

Wu, D., Tu, C., Xin, C., Xuan, H., Meng, Q., Liu, Y., Yu, Y., Guan, Y., Jiang, Y., Yin, X., Crameri, G., Wang, M., Li, C., Liu, S., Liao, M., Feng, L., Xiang, H., Sun, J., Chen, J., Sun, Y., Gu, S., Liu, N., Fu, D., Eaton, B.T., Wang, L.F., and Kong, X., Civets are equally susceptible to experimental infection by two different severe acute respiratory syndrome coronavirus isolates, J. Virol., 2005, vol. 79, no. 4 , pp. $2620-2625$.

https://dx.doi.org/10.1128\%2FJVI.79.4.2620-2625.2005

$\mathrm{Xia}, \mathrm{X}$., Extreme genomic CpG deficiency in SARS-CoV-2 and evasion of host antiviral defense, Mol. Biol. Evol., 2020. https://doi.org/10.1093/molbev/msaa094

Xiao, Y., Meng, Q., Yin, X., Guan, Y., Liu, Y., Li, C., Wang, M., Liu, G., Tong, T., Wang, L.F., Kong, X., and $\mathrm{Wu}, \mathrm{D}$., Pathological changes in masked palm civets experimentally infected by severe acute respiratory syndrome (SARS) coronavirus, J. Comp. Pathol., 2008, vol. 138, no. 4, pp. $171-179$.

https://dx.doi.org/10.1016\%2Fj.jcpa.2007.12.005
Yang, Y., Peng, F., Wang, R., Guan, K., Jiang, T., Xu, G., Sun, J., and Chang, C., The deadly coronaviruses: the 2003 SARS pandemic and the 2020 novel coronavirus epidemic in China, J. Autoimmun., 2020, vol. 109, p. 102434. https://dx.doi.org/10.1016\%2Fj.jaut.2020.102434

Ye, Z.W., Yuan, S., Yuen, K.S., Fung, S.Y., Chan, C.P., and Jin, D.Y., Zoonotic origins of human coronaviruses, Int. J. Biol. Sci., 2020, vol. 16, no. 10, pp. 1686-1697. https://dx.doi.org/10.7150\%2Fijbs.45472

Zhang, G., Cowled, C., Shi, Z., Huang, Z., Bishop-Lilly, K.A., Fang, X., Wynne, J.W., Xiong, Z., Baker, M.L., Zhao, W., Tachedjian, M., Zhu, Y., Zhou, P., Jiang, X., Ng, J., Yang, L., Wu, L., Xiao, J., Feng, Y., Chen, Y., Sun, X., Zhang, Y., Marsh, G.A., Crameri, G., Broder, C.C., Frey, K.G., Wang, L.F., and Wang, J., Comparative analysis of bat genomes provides insight into the evolution of flight and immunity, Science, 2013, vol. 339, no. 6118, pp. 456-460.

https://doi.org/10.1126/science.1230835

Zhang, Q., Zhang, H., Huang, K., Yang, Y., Hui, X., Gao, J., He, X., Li, C., Gong, W., Zhang, Y., Peng, C., Gao, X., Chen, H., Zou, Z., Shi, Z., and Jin, M., SARS-CoV-2 neutralizing serum antibodies in cats: a serological investigation, bioRxiv, 2020.

https://doi.org/10.1101/2020.04.01.021196

Zhao, S., Li, W., Schuurman, N., van Kuppeveld, F., Bosch, B.J., and Egberink, H., Serological screening for coronavirus infections in cats, Viruses, 2019, vol. 11, no. 8, p. 743. https://dx.doi.org/10.3390\%2Fv11080743

Zhu, S., Zimmerman, D., and Deem, S.L., A review of zoonotic pathogens of dromedary camels, Ecohealth, 2019, vol. 16 , no. 2 , pp. $356-377$.

https://doi.org/10.1007/s10393-019-01413-7

Translated by E. Makeeva 